\title{
List of sources
}

$\begin{array}{llll}\text { RIA Novosti } \quad \text { [RIA News]. } & \text { 03.10.2018. }\end{array}$ https://ria.ru/society/20181003/1529896382.html.

\section{ПРЕУВЕЛИЧЕНИЕ И ПРЕУМЕНЬШЕНИЕ КАК МАРКЕРЫ РЕЧЕВОГО РАЗВИТИЯ РЕБЁНКА: АКМЕОЛОГИЧЕСКИЙ ПОДХОД}

\section{И.П. Амзаракова}

Ключевые слова: речь ребёнка, «язык нянь», преувеличение, преуменьшение, акмеологический подход.

Keywords: child's speech, «language of nurses», hyperbole, diminution, acmeological approach.

\section{DOI 10.14258/filichel(2019)2-11}

Вторая половина двадцатого века ознаменовалась интенсивным развитием интердисциплинарных и трансдисциплинарных направлений в лингвистике: психо-, социо-, этно-, прагма-, юрислингвистика и др. Изучение языковой личности ребенка, факторов развития его коммуникативной компетенции происходит на стыке онтолингвистики и лингвоперсонологии, которые близко соприкасаются с принципами, заложенными в акмеологии. Путь к высшей ступени индивидуального развития начинается с раннего детства, и успешность этого пути зависит от эмоционального и интеллектуального общения ребёнка с близкими ему людьми. «Процесс усвоения родного языка ребёнком», - считает М.М. Бахтин, «есть процесс постепенного вхождения ребёнка в речевое общение. По мере этого вхождения формируется и наполняется содержанием его сознание» [Бахтин, 1998, с. 376].

Особенности языка ребёнка младшего школьного возраста диктуются психолингвистическими параметрами, а именно переходом от наглядно-образного мышления к формально-логическому (репрезентативному) мышлению, особенности речевого поведения тесно связаны с категорией пространства, с выходом ребёнка за рамки семьи в среду сверстников и «чужих» взрослых [Амзаракова, 2012, c. 277]. 
Ребёнок познает действительность в её объективных, реальных параметрах. Познание происходит через восприятие, одним из существенных принципов которого является константность и целостность [Выготский, 2004, с. 170, 173]: «Восприятие величины предмета, его цвета, формы, места в пространстве - всё это должно в ходе развития стать константным, независимым от условий наблюдения» [Выготский, 2004, с. 171].

Исследователи отмечают, что семантическая сторона детской речи развивается постепенно и тесно связана с когнитивным опытом, который ребёнок приобретает в результате практической деятельности и в процессе общения с взрослыми. Общение ребёнка определяется рамками трёх пространств его мира: миром вещей, миром языка и миром людей. В освоении пространственных параметров большую роль играет речь окружающих его людей, в первую очередь речь матери. Это явление описано в психолингвистической литературе как baby talk или «язык мам / язык нянь» [Ferguson, 1977], то есть как интонационно-просодически, лексически и синтаксически упрощённый язык, обращённый к ребёнку. Г. Сагун говорит о том, что упрощённый язык используют для общения с маленькими детьми не только матери, но и отцы, и не только для общения с маленькими детьми, но и с животными, даже с растениями и неживыми объектами [Szagun, 1993, s. 260]. Она отмечает далее, со ссылкой на работу Ч. Фергюсона [Ferguson, 1977], что каждый язык располагает таким упрощённым кодом для общения с детьми, иностранцами, слабослышащими и умственно отсталыми людьми. Более того, этот код имеет свои особенности в зависимости от этнической культуры. Заметное место в таком «материнском» языке занимают диминутивы, которые присутствуют во многих языках: ножки, ручки, doggy, ducky, Händchen, Füßchen, Kleidchen и т. п.

Преувеличение и преуменьшение представляют собой мыслительную операцию, при которой искажаются степень интенсивности признака и правдоподобие предмета, свойства или действия. Что-то преувеличить - значит представить в больших размерах, а преуменьшить - в меньших размерах, чем на самом деле [Ожегов, 1984, с. 506]. Средствами языковой репрезентации названных операций выступают в большинстве случаев гипербола и мейоза, которые рассматриваются в стилистике как фигуры речи либо как троп с «чрезмерным» преувеличением или преуменьшением, как отклонение от нейтрального и объективного стиля. Цель использования данных тропов - усиление впечатления, положительная или отрицательная оценка [Энциклопедический словарь-справочник, 
2005, с. 97, 175; Москвин, 2007, с. 198; Акбутина, 2011, с. 775]. Исследователи тропов обычно подчёркивают осознанность речевого действия, реализующего мыслительную операцию преувеличения.

В.П. Москвин приводит среди прочих определений гиперболы высказывание А.А. Потебни о том, что это «результат как бы некоторого опьянения чувством, мешающего видеть вещи в их настоящих размерах» [Москвин, 2007, с. 198], подчёркивая тем самым аффективную, эмоциональную природу данного феномена. Замечание об эмоциональной стороне явления имеет для нашего исследования принципиальное значение, поскольку мы ставим задачей рассмотреть, каким образом функционируют языковые средства преуменьшения и преувеличения в речи ребёнка, который по определению является homo sentiens.

Но если в стилистике и риторике явное преувеличение или преуменьшение сигнализируют об отклонении от нейтрального, объективного стиля с целью иронии, высмеивания или просто акцентирования внимания на объекте, то в детской речи эта категория свидетельствует о продвижении по ступенькам психофизиологического и когнитивного развития.

Гипербола, утверждает Л. Грузберг, «не только фиксация мысли, но и отражение особой формы творческого мышления, заключающейся в способности человеческой мысли отойти от реальности» [Грузберг, 2013].

Освоение ребёнком параметрических понятий и их языковое выражение издавна привлекают внимание лингвистов и психологов. Так, параметрическим прилагательным и их освоению детьми раннего возраста посвящает своё исследование Ю.С. Пузанова [Пузанова, 2011; 2013]. Она отмечает, что уже в возрасте двух с небольшим лет дети используют синонимы разных структурных типов: крошечные пуговички (2,0), холоднущая вода (2,3), эта хрюшка большаяпребольшая (2,1), У тебя как у клоуна, большие ботинки. Большущиепребольшущие! (2,3), Арбуз немножко громадненький $(3,8)$, толстенькое яблочко $(4,6)$, длинненький сон $(4,7)$ [Пузанова, 2011, c. 209].

По свидетельству Е.С. Трибушининой и Е.А. Дубинкиной, в речи русскоязычных детей используются такие средства выражения степени качества, как аналитические формы степеней сравнения (самый красивый), наречия степени (чуть-чуть), лексические замены (большой > огромный), редупликация (маленький-маленький, оченьочень), суффиксы (маленький > маленькее). Как видим, они создают основу для актуализации категории преувеличения/ преуменьшения. 
На основе наблюдений за речью нидерландских и русских детей авторы делают вывод о том, что скорость освоения детьми подобных средств выражения степени качества в разных языках различна. Чем сложнее и разнообразнее парадигматическая система средств выражения степени, тем медленнее идёт освоение [Трибушинина, Дубинкина, 2011, с. 170].

Использование при создании воображаемого предмета или ситуации таких приёмов, как преувеличение, преуменьшение, свидетельствует о развитии творческих способностей детей, что наблюдается уже в возрасте 3-4 лет. Дети дошкольного и младшего школьного возраста больше, чем взрослые, доверяют своей фантазии, что убедительно доказано Л.С. Выготским [Выготский, 1930]. Поэтому в своей речи они легко снабжают предметы и объекты гиперболизированными оценками: $A$ жаба сделала такой укол, который помогает от перелома. Это надо очень огромным иирицом, как наш дом! (4;4) (пример В.К. Харченко).

С одной стороны, дети младшего и дошкольного возраста употребляют экспрессивные гиперболы и мейозы (Собачка маленькая такая, как напёрсток!), а с другой, не понимают экспрессивного смысла преуменьшения, содержащегося во фразеологизмах в силу того, что воспринимают фразеологизм как свободное словосочетание (кот наплакал, один нос остался; см. об этом подробнее в [Усачева, 2013].) И.В. Мысан в результате эксперимента выяснил, что более 75 \% детей старшего дошкольного возраста неправильно объясняют значение фразеологизмов, более 90 \% детей могут объяснить значения компонентов-фразеологизмов, но не смысл [Мысан, 2016, с. 69-70].

Гиперболизация и преуменьшение как проявления особенностей детского восприятия зависят от речевого окружения в семье. Как упоминалось выше, в «языке нянь» используется большое количество диминутивов, что характерно для общения взрослых с ребёнком в европейской языковой культуре. Рассмотрим это на материале немецкого языка.

Проследим, как меняется речь партнёров по общению и доля диминутивов в ней в зависимости от возраста ребёнка. Представленные для анализа транскрипции из Дортмундского корпуса спонтанной детской речи (DOKO, 1996, 1998) ${ }^{1}$ фиксируют речь Николь - 1 год, 8 месяцев и Габи - 5 лет, 4 месяца.

\footnotetext{
1 Здесь и далее в круглых скобках даны ссылки на тексты из списка источников, приведенного в конце статьи.
} 
Анализ общения родителей с дочкой Николь $(1 ; 8)$ показывает наличие в речи взрослых большого количества уменьшительных слов, обращённых к ребёнку: Hansi, Piepsi. Реагирующая реплика ребёнка этого возраста представляет собой дословный повтор некоторых уменьшительных слов, в фонетической оболочке, свойственной его

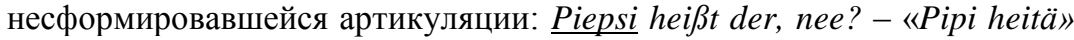
(DOKO, 1996, S. 52).

Мать:

dauert noch 'n Augenblickchen, ne, Schätzelein? (ibid., S. 62);

steck in's Mündchen (ibid., S. 13);

so, gleich müssen wir noch die Knöpfchen zumachen hier. So, diesen Knopf (ibid., S. 15);

das ist ein kleines Männchen auf deiner Hose, guck (ibid., S. 28).

Отец:

hat die nicht feine Härchen, die Puppa? schön an die Ärmchen fassen (ibid., S. 41)

pass mal auf, jetzt machen wir die Ärmchen von der Puppa auseinander (ibid., S. 41)

Представим результаты анализа транскрипций в таблице.

\begin{tabular}{|c|c|c|c|}
\hline $\begin{array}{l}\text { Класс } \\
\text { слов }\end{array}$ & Референция & мать & отец \\
\hline \multirow{4}{*}{ 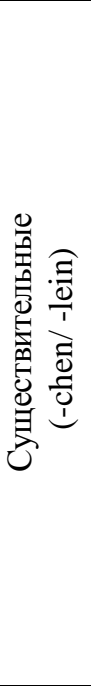 } & Разные слова (types) & 14 & 15 \\
\hline & $\begin{array}{c}\text { Словоупотребления } \\
\text { (tokens) }\end{array}$ & 31 & 46 \\
\hline & Адресовано ребёнку & $\begin{array}{c}\text { 6/20 (в т. ч. } 2 \\
\text { обращения) } \\
\text { Schätzchen } 1^{1} \\
\text { Schätzelein } 6 \\
\text { Küßchen } 6 \\
\text { Mündchen } 1 \\
\text { Schühchen } 3 \\
\text { Knöpfchen } 3 \\
\end{array}$ & $\begin{array}{c}6 / 20 \\
\text { Äuglein } 6 \\
\text { Fingerchen } 2 \\
\text { Füßchen } 1 \\
\text { Händchen } 4 \\
\text { Mündchen } 2 \\
\text { Schühchen } 5\end{array}$ \\
\hline & $\begin{array}{c}\text { Адресовано } \\
\text { предметам }\end{array}$ & $\begin{array}{c}6 / 9 \\
\text { Männchen 1 } \\
\text { Pferdchen } 2 \\
\text { Schwänzchen } 1 \\
\text { Stühlchen 2 } \\
\text { Töpfchen 2 } \\
\end{array}$ & $\begin{array}{c}\text { 8/25 } \\
\text { Ärmchen } 2 \\
\text { Blümchen } 2 \\
\text { Häpschen } 2 \\
\text { Härchen } 3 \\
\text { Häschen } 8 \\
\end{array}$ \\
\hline
\end{tabular}

\footnotetext{
${ }^{1}$ Цифра после слова в таблице означает количество произнесений соответствующего слова. - И.А.
} 


\begin{tabular}{|c|c|c|c|}
\hline & Pünktchen 1 & $\begin{array}{c}\text { Strümpfchen 1 } \\
\text { Tischchen 4 } \\
\text { Töpfchen 3 }\end{array}$ \\
\cline { 2 - 4 } & $\begin{array}{c}\text { Адресовано } \\
\text { действию }\end{array}$ & $\begin{array}{c}\text { Augenblickchen 1 } \\
\text { Küsschen 1 }\end{array}$ & $\begin{array}{c}1 / 1 \\
\text { Küsschen 1 }\end{array}$ \\
\hline Наречие & & $1 / 6$ bisschen & $1 / 15$ bisschen \\
\hline
\end{tabular}

Табл. 1. Диминутивы в общении с Николь $(1 ; 8)$.

Как видно из табл. 1, диминутивы в коммуникации родителей с ребёнком направлены как на самого ребёнка, так и на предметы, его окружающие. В речи отца диминутивов больше, как в количественном (43 слова против 30 в речи матери), так и в качественном отношении (15 разных слов против 14 в речи матери). Достаточно часто используется наречие bisschen ('немножко'), само по себе являющееся лексикализованным отымённым дериватом, образованным с помощью уменьшительного суффикса (cp. Biss - укус, кусок + уменьшительный суффикс -chen). Поскольку Николь ещё не говорит полными фразами, то выделить в её речи диминутивы не представлялось возможным.

Иную картину с использованием диминутивов наблюдаем в коммуникации с Габи (5;4). См. табл. 2. Окружающие её близкие люди - мама и девушка-экспериментатор - практически не употребляют уменьшительных слов, то есть «язык нянь» уже не используется ввиду того, что ребёнок к пяти годам полностью владеет структурой родного языка. Из таблицы видно, что диминутивы перемещаются из речи взрослых в речь ребёнка, который в игре имитирует манеру взрослых разговаривать с маленькими детьми. Сама Габи дублирует диминутив нейтральным синонимом: (рисует) die (das Mädchen, welches G malt) kriegt 'n ganz schönes Hüttchen / ganz schöne Hütte <...> Hütte Hütte dranmaln /// (kommentiert ihre Zeichnungen) so 'ne Hütte // is doch schön, (schnalzt mit der Zunge) da kommt das Babychen rein / kleines (DOKO, 1998, s. 52).

Диминутив приобретает реальное параметрическое обоснование: is 'n ganz kleines, fast wie ein Baby // kleines Kindchen (DOKO, 1998, s. 52) (= 'такой совсем маленький, почти как грудной ребёнок, маленький ребёночек') или же используется как имитация языка нянь в игре, о чём свидетельствует помета «Babysprache» («язык детей/нянь») и «lispelt» («сюсюкает») в транскрипции: Nora ich möchte 'n bisschen Nuntella / bisschen essen // (Babysprache) 'n bisschen Nutella essen (G lispelt) ... holst 'n Löffelchen hat se gesagt (ibid., S. 39). Или кормит куклу, перенося стереотип языка нянь на действие кормления куклы: 
Hier dein Breichen, meine Kleine, mach doch mal 'n Mündchen auf (ibid., S. 14).

\begin{tabular}{|c|c|c|c|c|}
\hline $\begin{array}{l}\text { Класс } \\
\text { слов }\end{array}$ & Референция & Нора, мать & $\begin{array}{c}\text { Марион, } \\
\text { эксперимен } \\
\text { татор }\end{array}$ & Габи $(5 ; 4)$ \\
\hline \multirow{5}{*}{ 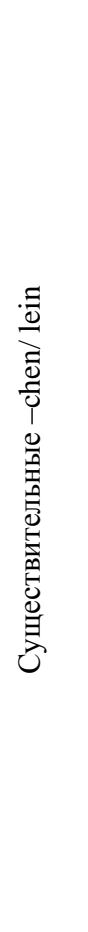 } & Разные слова (types) & 4 & 1 & 16 \\
\hline & $\begin{array}{c}\text { Словоупотребления } \\
\text { (tokens) }\end{array}$ & 5 & 1 & 19 \\
\hline & $\begin{array}{c}\text { Адресовано } \\
\text { ребёнку/кукле }\end{array}$ & $\begin{array}{c}1 / 1 \\
\text { Stimmchen } 1\end{array}$ & & $\begin{array}{c}\text { 3/3 } \\
\text { Babychen1 } \\
\text { Kindchen 1 } \\
\text { Mündchen 1 }\end{array}$ \\
\hline & $\begin{array}{c}\text { Адресовано } \\
\text { предметам }\end{array}$ & $\begin{array}{c}3 / 4 \\
\text { Kinderstühlchen } \\
1 \\
\text { Püppchen } 1 \\
\text { Süppchen } 2\end{array}$ & $\begin{array}{c}1 / 1 \\
\text { Würstchen } 1\end{array}$ & $\begin{array}{c}12 / 15 \\
\text { Bettchen 1 } \\
\text { Breichen } 3 \\
\text { Breilein 1 } \\
\text { Brötchen 1 } \\
\text { Ferkelchen 1 } \\
\text { Gänschen 1 } \\
\text { Hüttchen 1 } \\
\text { Löffelchen 1 } \\
\text { Kinderstühlch } \\
\text { en 1 } \\
\text { Schwänzchen } \\
1 \\
\text { Süppchen 2 } \\
\text { Töpfchen 1 }\end{array}$ \\
\hline & $\begin{array}{l}\text { Адресовано } \\
\text { действию }\end{array}$ & - & - & $\begin{array}{c}1 / 1 \\
\text { Tröpfchen } 1\end{array}$ \\
\hline 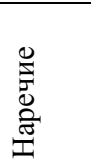 & & $\begin{array}{c}1 / 1 \\
\text { bisschen } 1\end{array}$ & $\begin{array}{c}1 / 2 \\
\text { bisschen } 2\end{array}$ & $\begin{array}{c}1 / 16 \\
\text { bisschen } 16\end{array}$ \\
\hline
\end{tabular}

Табл. 2. Диминутивы в общении с Габи (5;4).

Из таблицы видно, что пятилетняя девочка называет основные атрибуты кормления ребёнка, представленного в игре куклой, в уменьшительной форме, выражая отношение к маленькому по образцу поведения взрослых: она «кормит» куклу, поэтому самыми частотными номинациями в её речи являются 
кашка (Breichen, Breilein) и супчик (Süppchen). Все кухонные принадлежности в ситуации кормления куклы (читай: ребёнка) приобретают уменьшительность: ложечка (Löffelchen), кастрюлька (Töpfchen). Уговаривая куклу съесть хотя бы капельку (Tröpfchen), девочка активно (16 раз) использует наречие «чутьчуть», «немножко» (bisschen). Ср. с практически той же частотностью этого наречия в речи отца Николь (15 раз). Частично употребление диминутивов девочкой инициируется и поддерживается присутствующими при игре взрослыми: Kinderstühlchen, Süppchen.

Вернемся к влиянию внешних факторов на когнитивное и речевое развитие ребёнка, к которым в первую очередь относится ситуация общения и воздействие взрослого. Исследователи отмечают, что чем меньше ребёнок, тем большее влияние на него оказывают внешние факторы. Чем старше ребёнок, тем большее значение приобретают его социальный опыт, его потребность общения со взрослыми, во время которого уточняются и обогащаются представления о параметрах реальной действительности, о возможностях их преувеличения и преуменьшения.

C переходом в школу, когда основные единицы разных уровней языка уже усвоены, начинается процесс формирования дискурсивной компетенции ребёнка, переход на лингвокогнитивный и мотивационный (по Ю.Н. Караулову) уровень развития языковой личности. Диминутивы «детского» языка исчезают из повседневного лексикона ребёнка и используются им уже осознано с прагматическими целями, например, в обращении первоклассника к маленькой сестрёнке, желая задобрить её: Karolinchen, mein Bienchen, was hast du denn? (Krüss, 1995). Мейоза как средство преуменьшения используется при сравнении. Так, мальчик, подчёркивая маленький размер портового пароходика, называет его скорлупкой, напёрстком: eine Nußschale ist er, ein Fingerhut! (ibid.).

В речи ребёнка младшего школьного возраста всё чаще появляются экспрессивные средства - гиперболические сравнения и метафоры для выражения своего отношения к человеку и действию. Отчасти это происходит спонтанно, но осознанному использованию средств выразительности, в том числе гиперболе и литоте, как отмечают языковеды и педагоги, младших школьников следует обучать специально. См. об этом в [Бизикова, 2013]. Типичным разговорным преувеличением являются такие 
гиперболы, как сто раз сльшиал, вечность не видел, никогда не ел (в значении «давно не ел»), она в тыму раз красивее (нем.: Sie sieht tausendmal schöner aus). Такие детские гиперболические высказывания, как für nichts auf der Welt; der schönste Kuchen auf der Welt ('ни за что на свете'; 'бабушкин торт - самый лучший на свете') свидетельствуют об эгоцентризме ценностного мира ребёнка. Преувеличения дети чаще всего используют в отношении чувств и ощущений, что отражено в детской литературе: Mein Herz schlug so schnell und laut wie ein Presslufthammer. Nein, es klang wie ein Hagel von Kanonenkugeln, die rundherum die Wände zerschlugen (Marmon, 2015, S. 83); или: Mich würden dann keine zehn Pferde reinkriegen (ibid., S. 79). Распространёнными языковыми средствами детского преувеличения в немецком языке являются словообразовательные форманты типа Riesen-, то есть великан, великанный (Riesenloch, Rieseneiche, Riesenkrach и т.п.) или Mords(Mordsgeschrei, Mordshunger) и другие способы сравнения. Антропоцентричность детского восприятия ведёт к тому, что объектом сравнения выступает человек, а базой для сравнения мир животных или вещей (Er schwitzte und keuchte wie zwei Nilpferde), либо явления природы (Die Jungen liefen wie der Wind).

Таким образом, приобретая навыки оценки параметров внеязыковой действительности и её вербализации, ребёнок в своём личностном развитии шаг за шагом продвигается к акме как самореализации личности. Образное использование ребёнком параметрических значений в виде приёмов преуменьшения (мейоза) и преувеличения (гипербола) свидетельствует о восхождении по шкале эмоционального и интеллектуального развития, способствует становлению языкового сознания и представлений о мире в его реальных и ирреальных связях.

\section{Литература}

Акбутина А.С. Использование стилистических приёмов преувеличения и преуменьшения в целях выражения иронии в языке немецкой прессы // Вестник Башкирского университета. 2011. Т. 16. № 3.

Амзаракова И.П. Ребёнок: язык, текст, коммуникация. Абакан, 2012.

Бахтин М.М. (Волошинов В.Н.) Марксизм и философия языка // М.М. Бахтин. Тетралогия. М., 1998.

Бизикова О.А. Развитие речи-рассуждения у детей дошкольного возраста. Нижневартовск, 2013.

Выготский Л.С. Воображение и творчество в школьном возрасте М., 1930.

Выготский Л.С. Вопросы детской психологии. СПб., 2004. 
Грузберг Л. Гипербола в живой разговорной речи. Постановка проблемы // Филолог. 2013. Вып. $24 . \quad$ [Электронный pecypc]. URL: http://philolog.pspu.ru/module/magazine/do/mpub_24_507.

Москвин В.П. Выразительные средства современной русской речи. Тропы и фигуры. Ростов н/Д., 2007.

Мысан И.В. Понимание и использование фразеологизмов детьми старшего дошкольного возраста // Проблемы онтолингвистики - 2016. Иваново, 2016.

Ожегов С.И. Словарь русского языка. М., 1984.

Пузанова Ю.С. Освоение антонимо-синонимических блоков параметрических прилагательных размера русскоязычными детьми // Проблемы онтолингвистики - 2013. СПб, 2013.

Пузанова Ю.С. Психолингвистические основы освоения детьми парадигматических отношений на материале параметрических прилагательных русского языка // Проблемы онтолингвистики - 2013. СПб., 2013.

Трибушинина Е.С., Дубинкина Е.А. Выражение степени качества нидерландскими и русскими детьми // Онтолингвистика - наука XXI века. СПб., 2011.

Усачева О.А. К вопросу об употреблении фразеологизмов с семантикой интенсивности в русском языке // Проблемы онтолингвистики - 2013. СПб., 2013.

Энциклопедический словарь-справочник. Выразительные средства русского языка и речевые ошибки и недочеты. М., 2005.

Ferguson C. Baby talk as simplified register // Talking to Children. Cambridge, 1977.

Szagun G. Sprachentwicklung beim Kind: eine Einführung. Weinheim, 1993.

\section{Список источников}

DOKO: Dortmunder Korpus der spontanen Kindersprache. Bd. 12: Teilkorpus Nicole (1;8). Essen, 1996; Bd.15: Teilkorpus Gabi (5;4). Essen,1998.

Krüss J. Sonntagmorgen-Geschichten. Frankfurt am Main, 1995.

Marmon U. Mein Freund Salim. Bamberg, 2015.

\section{References}

Akbutina A.S. Ispol'zovanie stilisticheskih prijomov preuvelichenija i preumen'shenija $v$ celjah vyrazhenija ironii v jazyke nemeckoj pressy [Using Stylistic Devices of Exaggeration and Understatement to Express Irony in the Language of the German Press] Vestnik Bashkirskogo universiteta [Bulletin of Bashkir University]. 2011. Vol. 16. No. 3.

Amzarakova I.P. Rebjonok: jazyk, tekst, kommunikacija [Child: Language, Text, Communication]. Abakan, 2012.

Bahtin M.M. (Voloshinov V.N.) Marksizm i filosofija jazyka [Marxism and Language Philosophy]. Tetralogija [Tetralogy]. Moskva, 1998.

Bizikova O.A. Razvitie rechi-rassuzhdenija u detej doshkol'nogo vozrasta [Development of the Reasoning Discourse of the Preschool Children]. Nizhnevartovsk, 2013.

Vygotskij L.S. Voobrazhenie $i$ tvorchestvo v shkol'nom vozraste [Imagination and Creativity at School Age]. Moskva, 1930.

Vygotskij L.S. Voprosy detskoj psihologii [Issues of Child's Psychology]. SanktPeterburg, 2004.

Gruzberg L. Giperbola v zhivoj razgovornoj rechi. Postanovka problemy [Hyperbole in the Colloquial Speech. Formulation of the problem] // Filolog [Philologist]. 2013. Iss. 24. URL: http://philolog.pspu.ru/module/magazine/do/mpub_24_507 (accessed 05.12.2017). 
Moskvin V.P. Vyrazitel'nye sredstva sovremennoj russkoj rechi. Tropy $i$ figury [Expressive Means of the Contemporary Russian Speech]. Rostov na Donu, 2007.

Mysan I.V. Ponimanie i ispol'zovanie frazeologizmov det'mi starshego doshkol'nogo vozrasta [Comprehension of Phraseological Means by Senior School Children]. Problemy ontolingvistiki - 2016 [Issues of Developmental Psycholinguistics - 2016]. Ivanovo, 2016.

Ozhegov S.I. Slovar' russkogo jazyka [The Russian Comprehensive Dictionary]. Moskva, 1984.

Puzanova Ju.S. Osvoenie antonimo-sinonimicheskih blokov parametricheskih prilagatel'nyh razmera russkojazychnymi det'mi [Mastering of Antonyms and Synonyms of Parametric Size Adjectives by Russian Children]. Problemy ontolingvistiki - 2013 [Issues of Developmental Psycholinguistics - 2013]. Sankt-Peterburg, 2013.

Puzanova Ju.S. Psiholingvisticheskie osnovy osvoenija det'mi paradigmaticheskih otnoshenij na materiale parametricheskih prilagatel'nyh russkogo jazyka [Psycholinguistic Grounds of Paradigmatic Mastering by Children as Exemplified with the Russian Parametric Adjectives]. Problemy ontolingvistiki - 2013 [Issues of Developmental Psycholinguistics 2013]. Sankt-Peterburg, 2013.

Tribushinina E.S., Dubinkina E.A. Vyrazhenie stepeni kachestva niderlandskimi $i$ russkimi det'mi [Actualization of the Quality Degree by Russian and Netherlandic Children]. Ontolingvistika - nauka XXI veka [Developmental Psycholinguistics - Science of XXI century]. Sankt-Peterburg, 2011.

Usacheva O.A. K voprosu ob upotreblenii frazeologizmov s semantikoj intensivnosti $v$ russkom jazyke [On Using Phraseological Units and Semantic Intensity in the Russian Language]. Problemy ontolingvistiki - 2013 [Issues of Developmental Psycholinguistics 2013]. Sankt-Peterburg, 2013.

Jenciklopedicheskij slovar'-spravochnik. Vyrazitel'nye sredstva russkogo jazyka $i$ rechevye oshibki $i$ nedochety [Encyclopedic Dictionary-Reference. Expressive Means of the Russian Language and Speech Errors]. Moskva, 2005.

Ferguson C. Baby talk as simplified register. Talking to Children. Cambridge, 1977.

Szagun G. Sprachentwicklung beim Kind: eine Einführung. Weinheim, 1993.

\section{List of sources}

DOKO: Dortmunder Korpus der spontanen Kindersprache. Bd. 12: Teilkorpus Nicole (1;8). Essen, 1996; Bd.15: Teilkorpus Gabi (5;4). Essen, 1998.

Krüss J. Sonntagmorgen-Geschichten. Frankfurt an Main, 1995.

Marmon U. Mein Freund Salim. Bamberg, 2015. 